Z. Sadeghi Dehkordi ${ }^{1^{*}}$, M. Mohammadpour ${ }^{2}$, S. Moradi ${ }^{3}$, M. J. Bahrami ${ }^{2}$, B. Kordi

1. Department of Parasitology, Faculty of Para Veterinary Science, Bu Ali Sina University, Hamedan, Iran

2. BSc of Veterinary Medicine Laboratory Science, Faculty of Para Veterinary Science, Bu Ali Sina University, Hamedan, Iran

3. Expert in Parasitology and Mycology Laboratory, School of Veterinary Medicine, BuAli Sina University, Hamedan, Iran

4. Msc of Veterinary Parasitology, Faculty of Para Veterinary Science, Bu Ali Sina University, Hamedan, Iran

\section{Survey of Fungal Contamination of Hamedan Indoor Swimming Pools in 2016}

Received:23 Dec.2016; Accepted:25 Apr.2017

\section{Abstract}

Background: The use of public places such as swimming pools and saunas, including ways of transmission of cutaneous fungal infections in humans. SO, Study the causes of opportunistic and pathogen fungi can be very useful in these areas to eliminate the contamination or reduce it and thus possible infection is prevent. Therefore, this study aimed to determine the fungal Contamination of Hamedan indoor Swimming Pools in 2016.

Methods: In this study, 3 indoor swimming pools of Hamedan, during 9 months 2016 in terms of fungal contamination were studied. To determine fungal contamination(saprophyte and dermatophyte) of the sample, Sampling of water in test tubes in a sterile screw and samples from different environmental surfaces in each pool (shower, dressing room surface, the chair and sit in the sauna, bath, platforms, around the pool) sterile carpet collection method was used. The samples separately on the specific media (Mycosyle Agar and SDA were inoculated and cultured using standard methods.

Results: Results of the present study showed that from all the 720 cultivated samples, 513sampleswere positive for one or more fungal contamination including 288 mould saprophyte 56.14\%), 216 yeast saprophyte (42.1\%) and 9 dermatophyte pathogenic fungi (1/75\%).

Conclusion: The results of this study show that although most of fungal contamination were Saprophytic and few were dermatophyte, but the low number of fungal infections in dealing with host, High risk of developing asthma and allergic diseases are dangerous.

Keywords: Swimming pool, Fungal contamination, Hamedan 


\section{برر سى آلودَّىهاى قارجى استخر هاى سريوشيده شهر همدان در سال هqسז-1)}

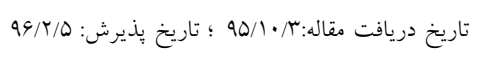

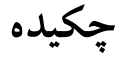

زمينه و هدف: استفاده از اماكن عمومى مثل استخر و سونا از جمله راههاى سرايت عفونتهاى قارجى جلدى در انسان به

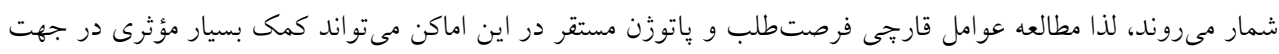

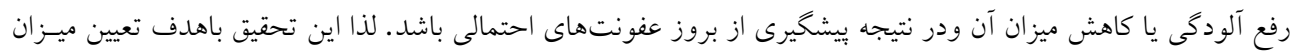

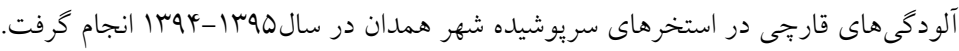

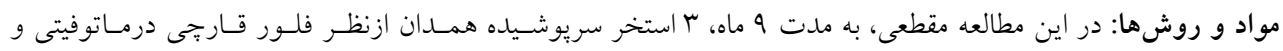

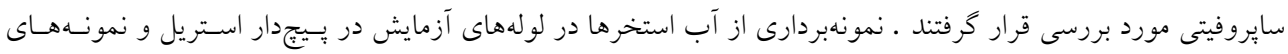

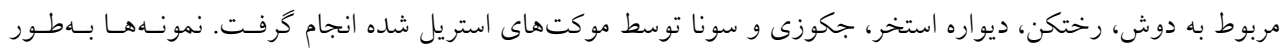

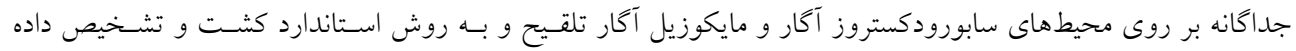

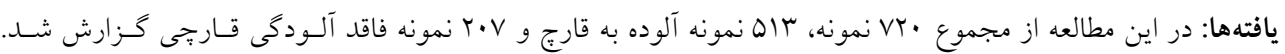

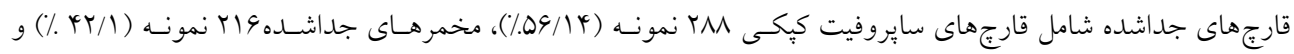

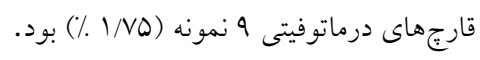
نتيجه گيرى: نتايج اين بررسى نشان مىدهد كه اخرجهه بيشتر آلودخى هاى قاريجى از نوع سايروفيت بودند، اما همان تعداد كم

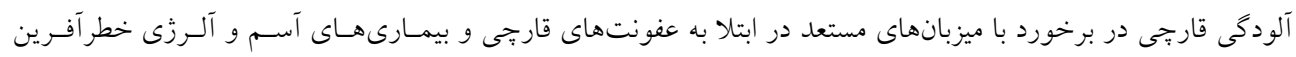
هستند. كلمات كليدى: آلودگى قارجى، استخرهاى شنا، شهر همدان جــابتتـرين مكــانهـاى ورزشسى تفريحسى تبـــيل مسىشـوند و

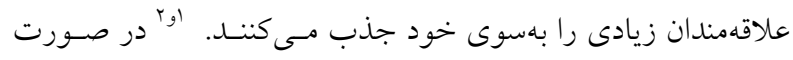

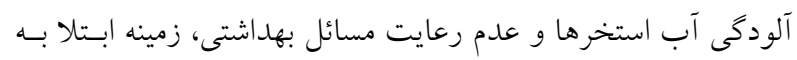
انواع عفونت ها، بيمارىهاى يوستى و قارجى در شناخران به وجـود

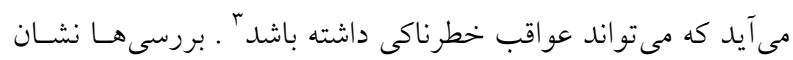

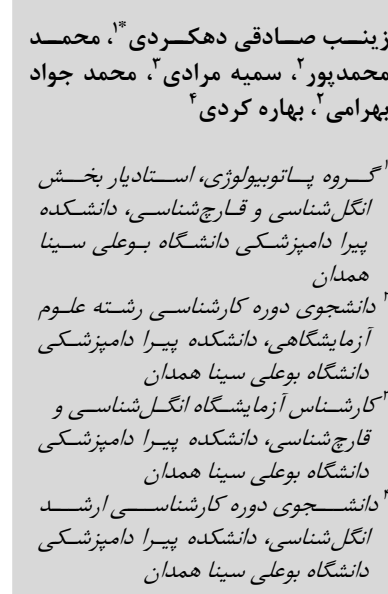

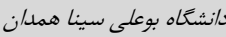

شدنل 
از كسب مجوز از سـازمان تربيـتبــنى شهرسـان همــان و تهيـــ جكليست جهت بررسى و جمع آورى اطلاعات لازم به استخرهاى

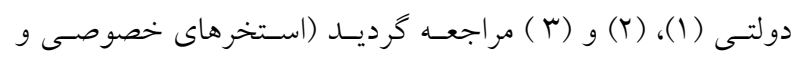
استخرهاى مربوط به مراجعان خاص و همجنين واحدهاى مسكونى

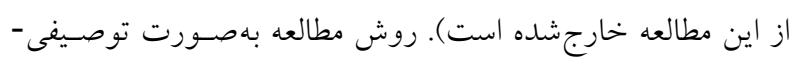

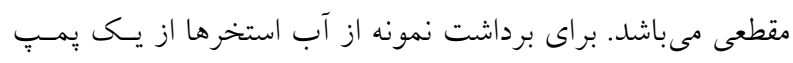

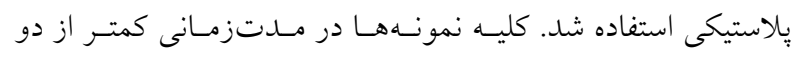

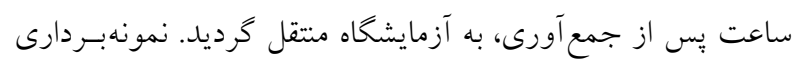

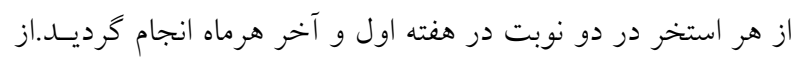

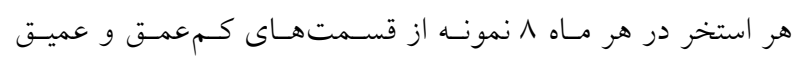

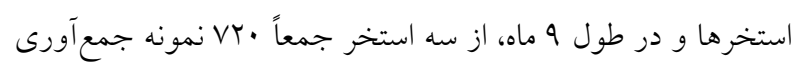
كرديد. (تعداد ·ب نمونه از سطوح محيطى مختلف هر استخر شـامل

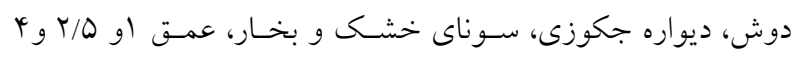

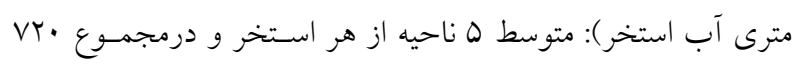

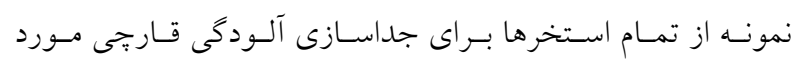

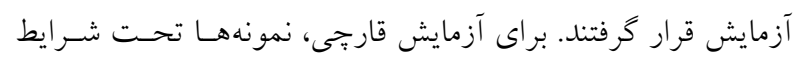

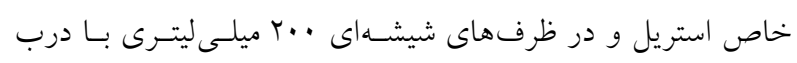

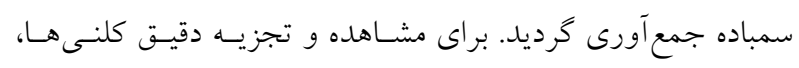

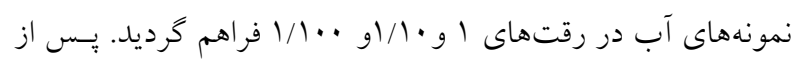
تهيه رقتها، از هر رقت به ميزان اميلى ليتر توسط كاغذهاى استريل روى محيطهاى كشت قارج شامل سابرودكستروز آكار و مايكوزيل

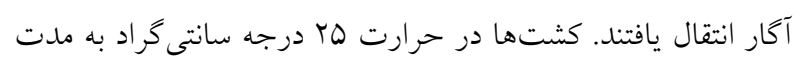

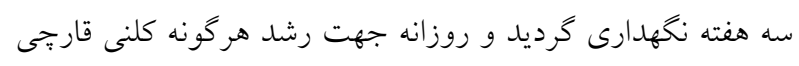

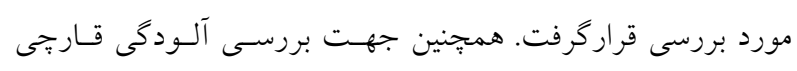

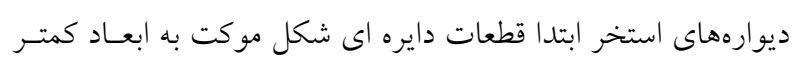

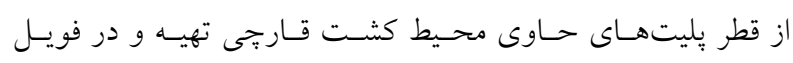

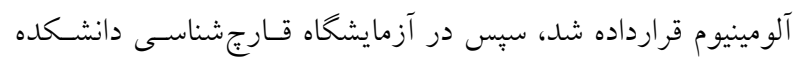

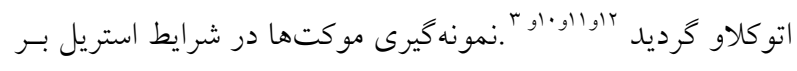
روى محيط كشتهاى مذكور تكان داده شـدند تـا عناصـر قـاريجى

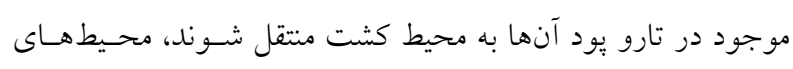

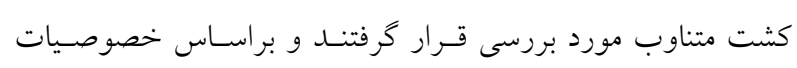

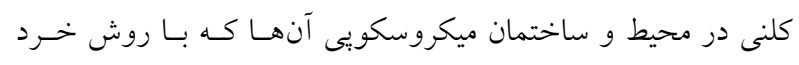
كردن و كشت روى لام انجامخرديد، قارج ها شناسايى شدند.
مىدهد كه علاوه بر آب، محيط فيزيكى استخرها نيـز بـه دليـل دارا

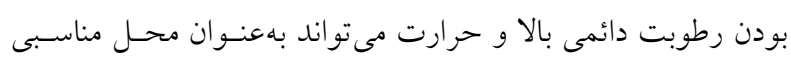

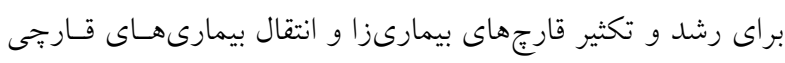

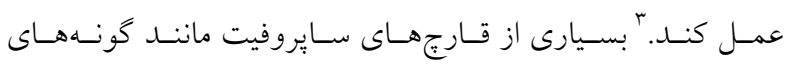

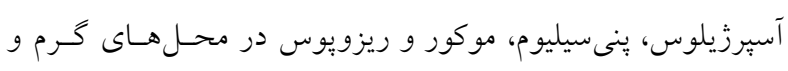

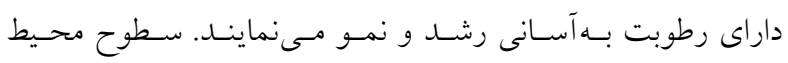

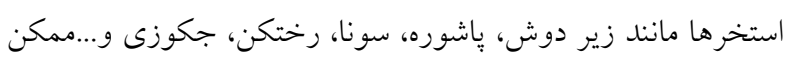

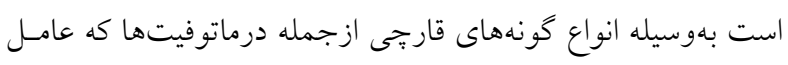
بيمارىهاى قارجى سطحى و جلدى مانند كجلى ها مىباشـند آلـوده

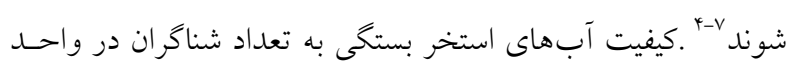

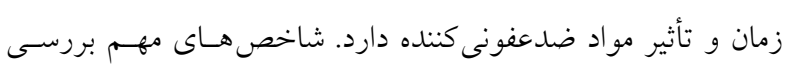

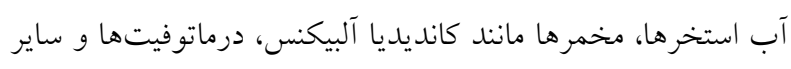

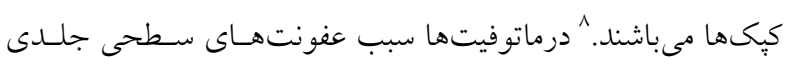

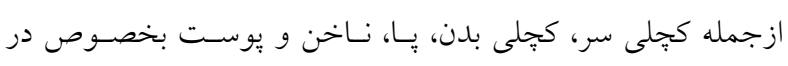

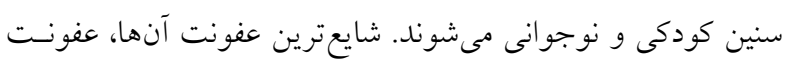

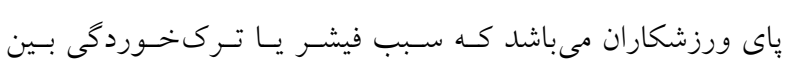

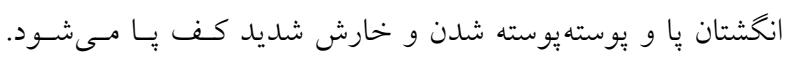

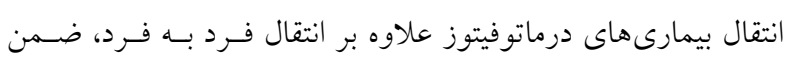

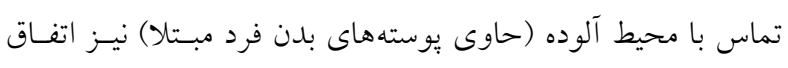

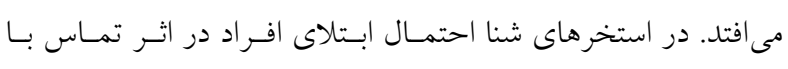

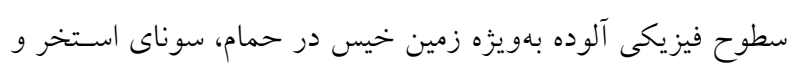

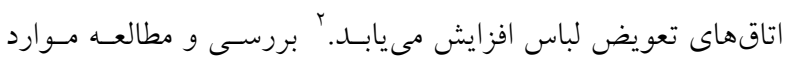

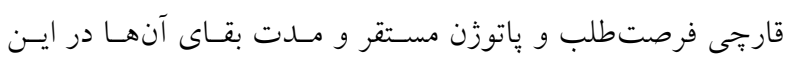

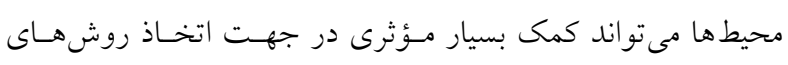

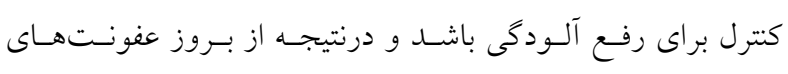

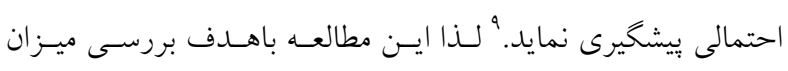
آلودكى قارجى سطوح فيزيكى استخرهاى شهر همدان طى شهريور

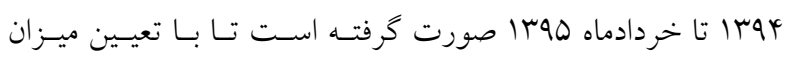
آلودكى هاى مزبور، نتايج در اختيار مسئولين ذيـربط جهـت ارتقـاى وضع بهداشتى استخرها قرار كيرد.

روش بررسى به منظور تعيين آلودكى هاى قارجى استخرهاى عمومى شنا، يُ 
ديـواره جكــوزى و آب اسـتخرها جـــا كرديســـ از 9 نمونـه داراى

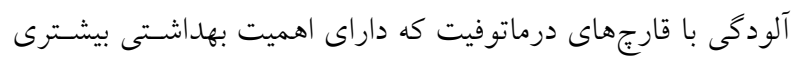

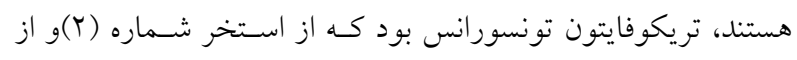

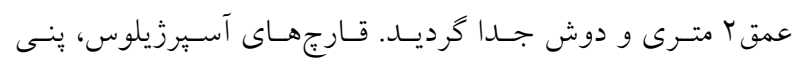

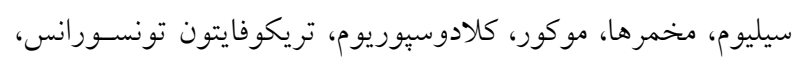

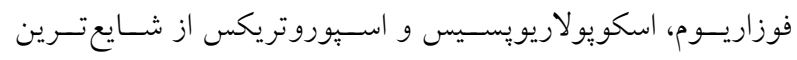

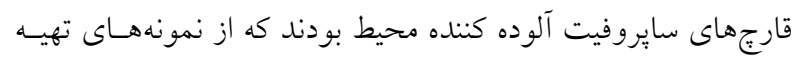
شده از سطوح مختلف محيطى استخرهاى مورد بررسى جدا شـائند

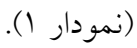

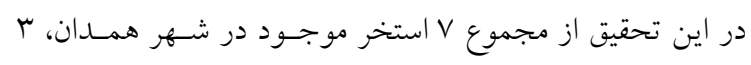
استخر فعال سريوشيده مورد بررسى قرار كرفـت كـه از •VT نمونسه

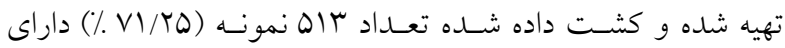

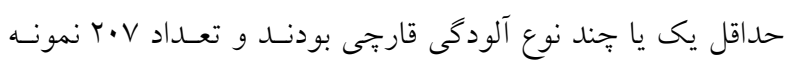

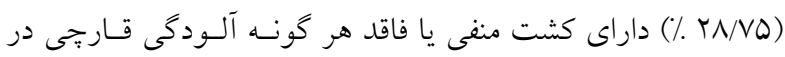

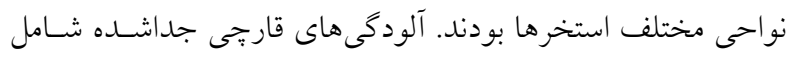

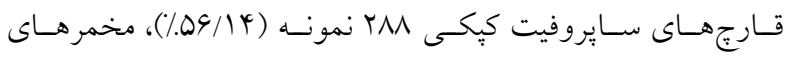

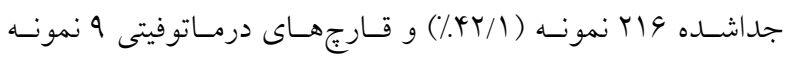

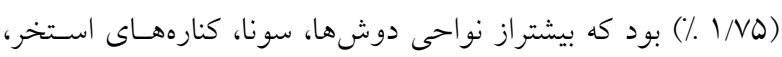

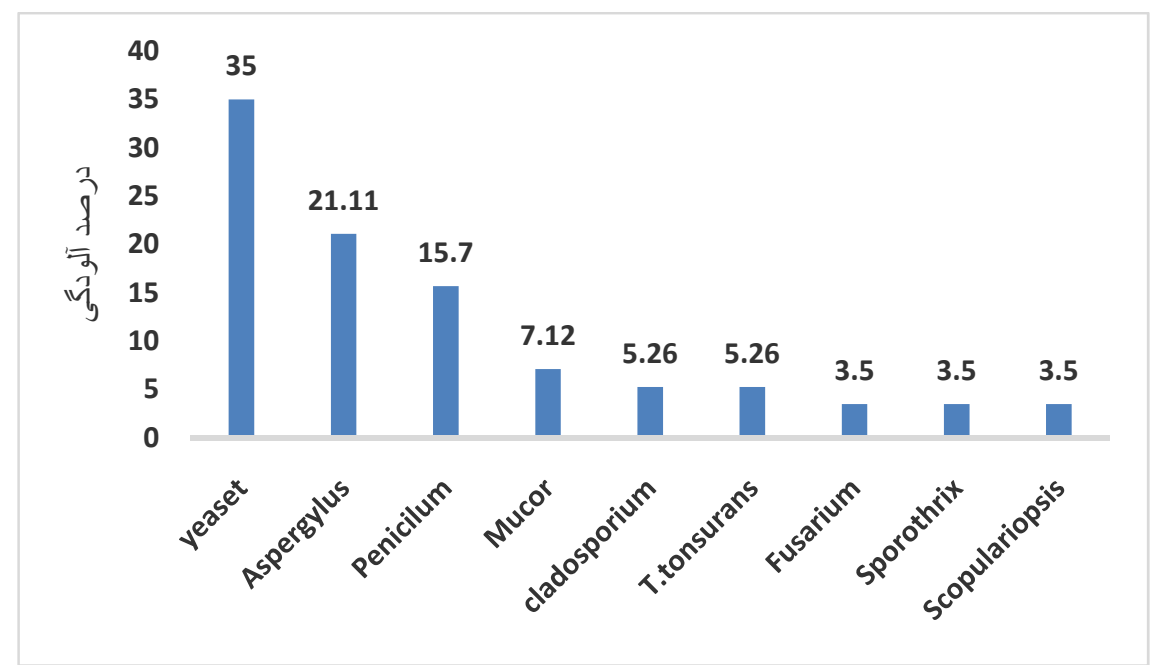

نمودار ا: توزيع فراوانى درصد قارجهاى سايروفيت جداشده از كشت نمونههاى سطوح محيطى استخرهاى شنا همدان

جدول ا: توزيع فراوانى قارجهاى جدا شده از نواحى مختلف استخرهاى مورد مطالعه

\begin{tabular}{|c|c|c|c|c|c|c|}
\hline \multicolumn{2}{|c|}{ درماتوفيت } & \multicolumn{2}{|c|}{ سايروفيت مخمرى } & \multicolumn{2}{|c|}{ سايروفيت كيكى } & \multirow[t]{2}{*}{ محل نمونه گيرى } \\
\hline درصد & تعداد & درصد & تعداد & درصد & تعداد & \\
\hline \multirow[t]{6}{*}{$I T / V$} & 9 & $\Delta \psi / D$ & $1 \cdot 1$ & $09 / \Gamma$ & $|V|$ & دوش \\
\hline & - & TYN & 40 & rQ & VT & سونا \\
\hline & - & $4 / 0$ & 9 & G/TO & 11 & جكوزى \\
\hline & - & $r / 0$ & 9 & $r / l$ & 9 & آب استخر \\
\hline & - & $1 \pi / 9$ & rV & $9 / T \Delta$ & 11 & ديو اره استخر \\
\hline & $I T / V$ & $99 / 1$ & 191 & $99 / 9$ & TM & جمع \\
\hline
\end{tabular}




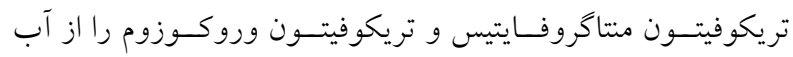

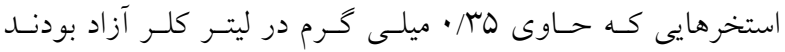

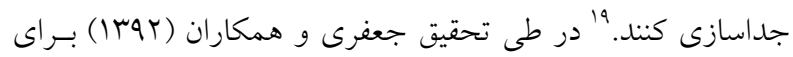
تعيسين ميـزان آلـودگى قـارجى اسـتخرهاى سريوشسيده شهـر يـزد، قسمتهاى مختلف استخر مانند كف، دوش رختكن و آب استخرها

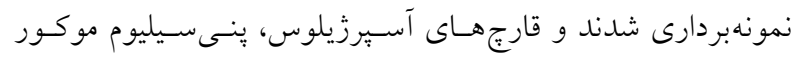

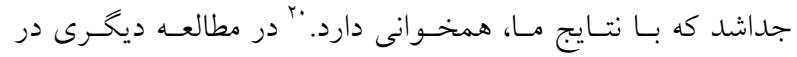

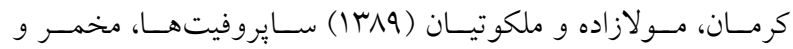

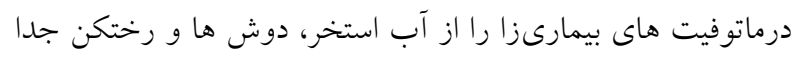

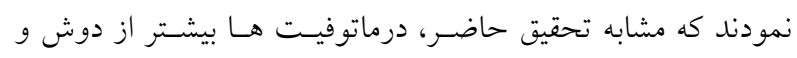

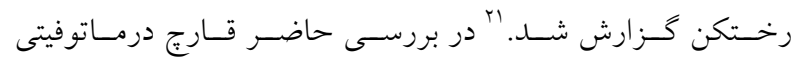

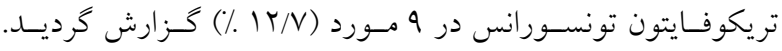

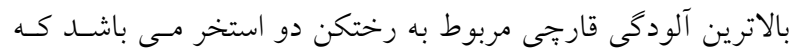

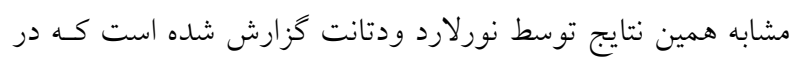

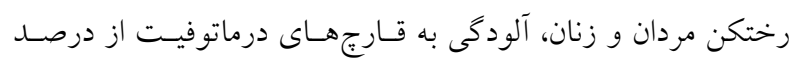

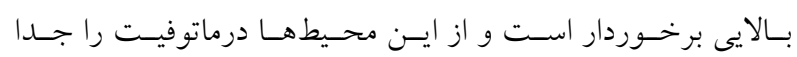

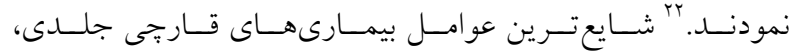

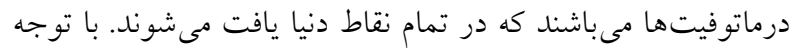

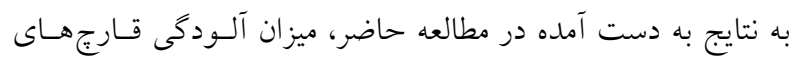
درماتوفيت در رختكن و دوش بيش از سـاير نقـاط استخرها بـود.

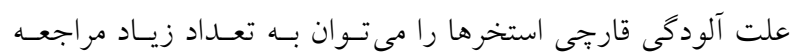
كنده در هر روز و قديمى بودن ساختمان استخر و نداشتن موقعيت مناسب دانست در حالى كه استخرى با كمترين مر اجعه كننده و تازه ساخت بودن ساختمان استخر و مطابقت بـا استانداردهاى جهانى، داني،

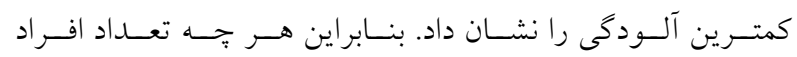

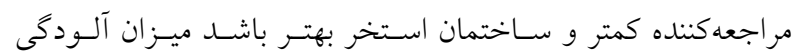

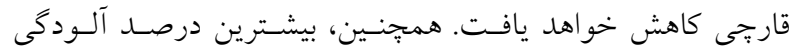

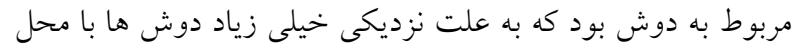

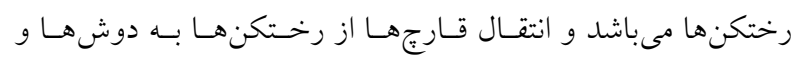

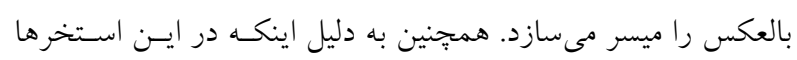

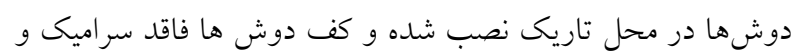
كاشى بوده، عناصر قارجى به راحتى مى توانند در اين مناطق مانـــه

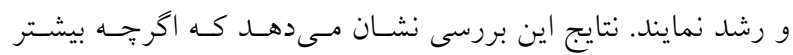

نتايج حاصله نشانكر وجود آلودخى هاى قـاريى در استتخرهاى

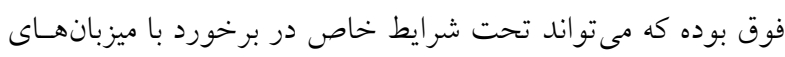

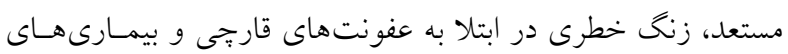

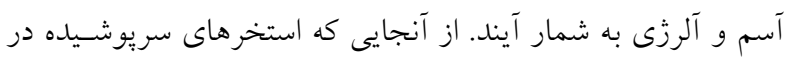

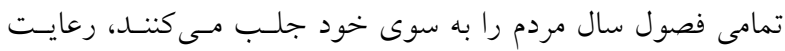

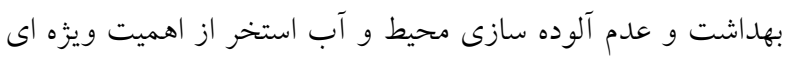

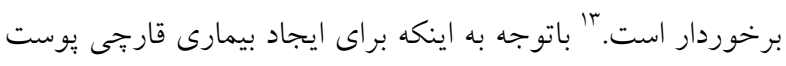

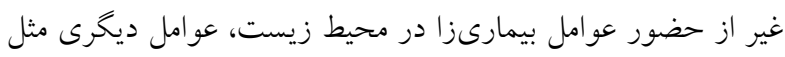

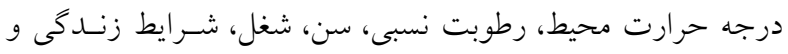

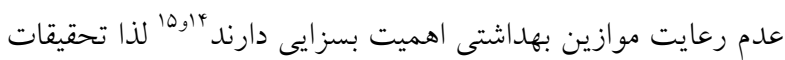

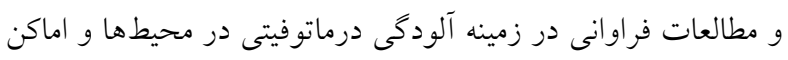

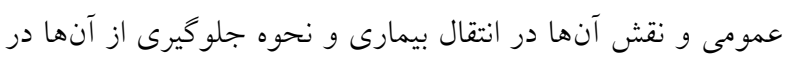

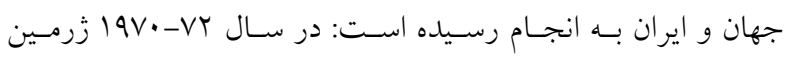

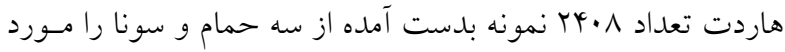

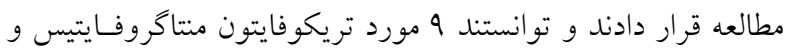

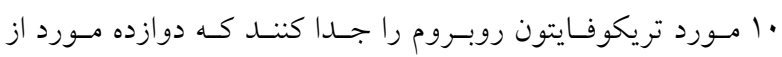

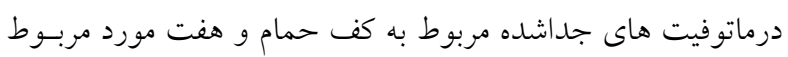

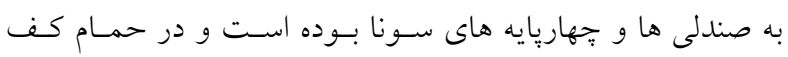
سنكى آلودكى درماتوفيتى كزارش نشده است، در صورتى كه از دو

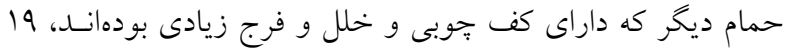

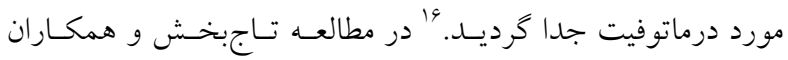

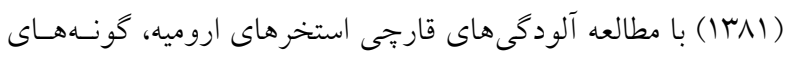

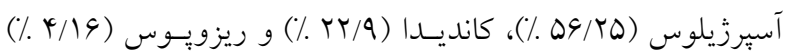

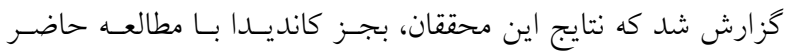

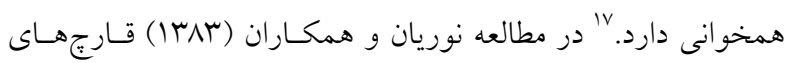
بيماريزاى درماتوفيتى(تريكوفايتون منتاكروفــيتيس و اييـدرموفايتون

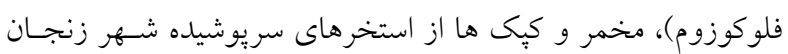

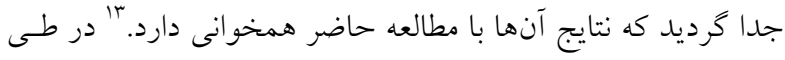
تحقيقى كه توسط مخازى و همكاران بر روى دو استخر شناى شهر

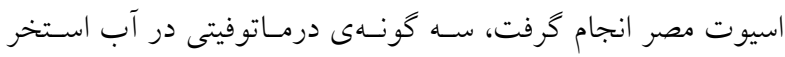

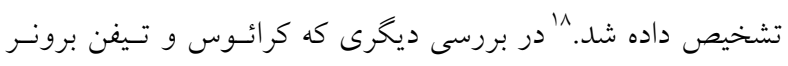

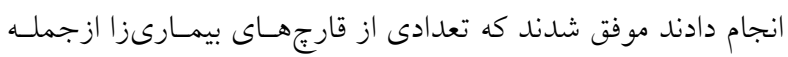




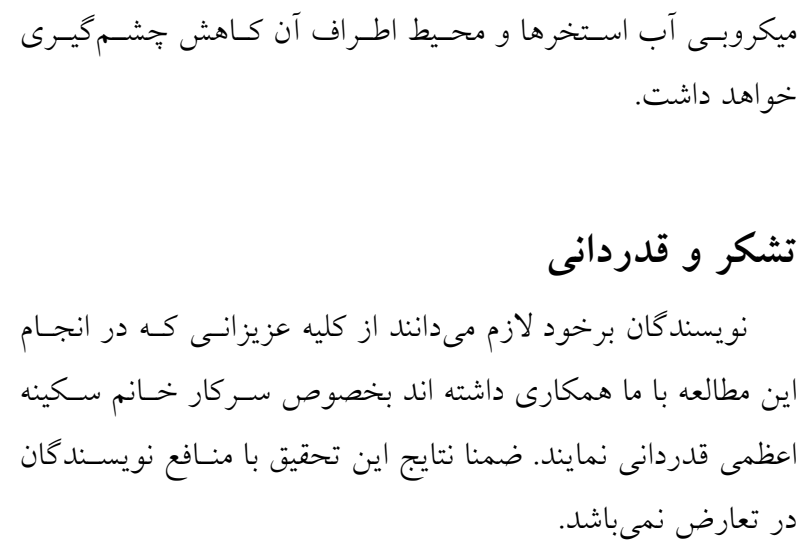

نويسندكان برخود لازم مى دانند از كليه عزيزانسى كـه در انجـام

اين مطالعه با ما همكارى داثته اند بخصوص سـر كار خـانم سـكينه

اعظمى قدردانى نمايند. ضمنا نتايج اين تحقيق با منــافع نويسـندكان$$
\text { در تعارض نمىباشد. }
$$

1. Schets FM, Schijven JF, Roda D. Exposure assessment for swimmers in bathing waters and swimming pools. Water Research. 2011; 45(7): 2392-400.

2. Rabi A, Khader Y, Alkafajei A, et al. Sanitary Conditions of Public Swimming Pools in Amman ,Jordan. Int J Environ Res Pub Health. 2008; 5(3): 152-7.

3. Nourian AA, Badali $H$, Hamzhei $H$. Fungal contamination in indoor swimming pools in Zanjan -Iran 2005. Pak J Bio Sci. 2006; 9(13):2524-7.

4. Rafiei AA. Fungal Contamination of Indoor Public Swimming Pools, Ahwaz, South-west of Iran. Iran J Pub Health. 2010; 39:124-8.

5. Nanbakhsh H, Diba K, Hazrati Tapeh Kh. Study of fungal and parasitic contamination of public swimming pools in Urmia, Iran. Sci J Kurdistan Uni Med Sci. 2005;10:26-30 [In Persian].

6. Detandt M, Nolard N. Fungal contamination of floors of swimming pools, particularly subtropical swimming paradises. Mycoses. 1995; 38(11-12): 509-13.

7. Hilmarsdottir I, Haraldsson H, Sigurdardottir A. Dermatophytes in a swimming pool facility: difference in dermatophyte load in men's and women's dressing rooms. Acta Derm Venereol. 2005; 85(3): 267-8.

8. American public Health Association standard Methods for the examination of water and waste 19 th.ed American public Health association, Inc. 1995 ; Honoree , Maryland , 213B , . 9221 C,E. 9060 A, 9230B, 9010 B.

9. Attye A, Auger P, Jolly J. Incidence of occult athlete's food in swimmers. Eur J of Epidemiol. 1990; 6: 244-7.

10. Rafiei AA. Fungal Contamination of Indoor Public Swimming Pools, Ahwaz, South-west of Iran. Iran J Pub Health. 2010; 39:124-8.
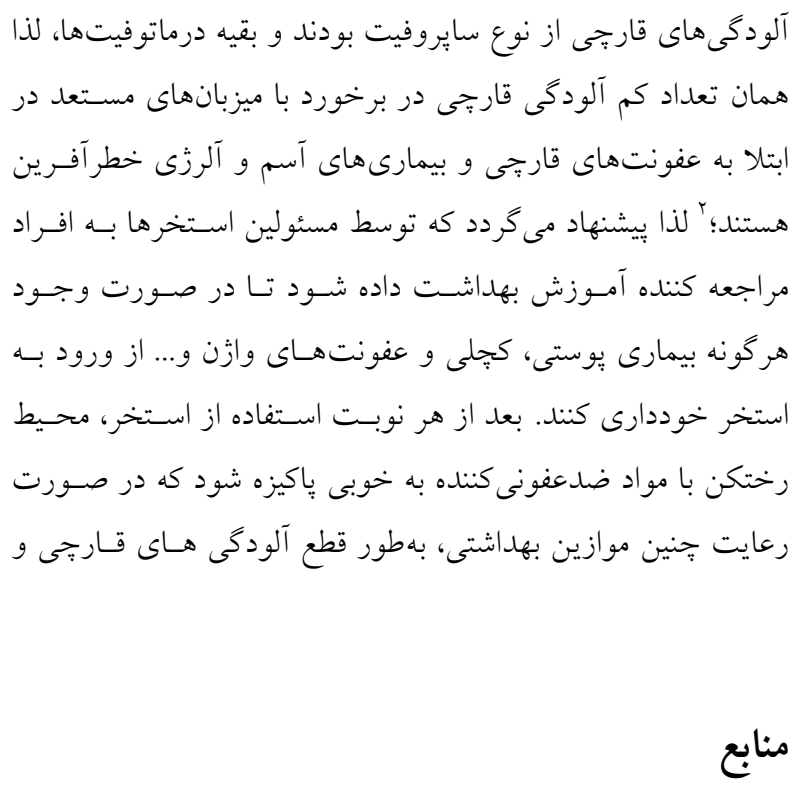

11. Detandt M, Nolard N. Fungal contamination of floors of swimming pools, particularly subtropical swimming paradises. Mycoses. 1995; 38(11-12): 509-13.

12. Shadzi Sh, Pour Moghadas H, Zare A. Fungal contaminations in four swimming pools in Isfahan. Iran J Pub Health. 2010; 39(3)124-8 [In Persian].

13. Nourian AA, Badali $H$, Hamzeii $H$. Fungal Contamination of Indoor Public Swimming Pools ,Zanjan in 1382. J Zanjan Univ Med Sci And Health Services. 2004; 48(12): 62 [In Persian].

14. Zieni F, Mahbodamir SA, Emami M. Medical Mycology, 1th ed. Tehran: Tehran University. 1998: 85-146 [In Persian].

15. Rippon J.W. Medical Mycology. Third ed Philadelphia: W.B Saunders Pub. 1988: 169-276.

16. Gemieinhard $H$, Lange $H$. The incidence of dermatophytes on souna baths. Dermatologische monotsschrift . 1974 feb; 4: 268-72.

17. Nanbakhsh H, Hazraty Kh, Rahbar M, Salary S, Diba K, Sayfer A. Study of fungal and parasitic contamination of public swimming pools in Urmia, Iran . J Urmia Univ Med Sci. 2002; 13(2):118-127.

18. Magahazy SMN. Fungi in two swimming pools in Aussit town Egypt. Zentralbl Microbial .1989; 144:213-16.

19. Kraus H. TieFenbrunner F. Randomised investigation of some tyrolean swimming pools for presence of trichomonas vaginal is and pathogenic fungi. Zentralbl Bakteriol (Orig B). 1975; 160(3):286-91.

20. Jafari AA, Ghaneian MT, Ehrampoush MH, Zarei S . Survey of Fungal Contamination in Surfaces of Yazd indoor Swimming Pools in 2011. J Shahid Sadoughi Univ Med Sci And Health Services. 2013; 12(2). 
21. Mollazadeh P, Malakutian M. Survey of Fungal Contamination and chemical tests of Swimming Pools in Kerman.13th National Congress On Environmental Health, Kerman Univ Med Sci. 2010 [In Persian].

22. Detanndt M, Norlard. N. Dermatophytes and swimming pools: seasonal fluctuation. Mycose. 1988; 31(10) 495500 .

23. Shadzi Sh, Chavdegani M. Survey of Fungal
Contamination of Swimming Pools in Isfahan. $\mathrm{J}$ water and Waste Water. 1993; 10: 3-6.

24. Shadzi Sh. Medical Mycology , 5th ed. Isfahan: Jahad daneshgahi Isfahan. 2004: 93-149, 271-279 [In Persian].

25. APHA, WPCE. Standard Methods for the Examination of Water and Waste Water .16th ed. USA: APHA, WPCE . 1985: 133-139, 974. 